\title{
"Is there anybody else out there?" - First Insights from a Suspect Screening for Phytotoxins in Surface Water
}

\author{
Barbara F. Günthardtabc, Carina D. Schönseeac, Juliane Hollender ${ }^{\text {bc }}$, Konrad Hungerbühler ${ }^{d}$, \\ Martin Scheringer ${ }^{c}$, and Thomas D. Bucheli ${ }^{* a}$
}

\begin{abstract}
To protect themselves, plants can produce toxic secondary metabolites (phytotoxins) that appear with widely varying structures and negative effects. These phytotoxins often show similar properties as known aquatic micropollutants in terms of mobility, persistence, toxicity, and possibly also ecotoxicity. However, their occurrence in surface waters remains largely unknown, which is also due to unknown ability of available screening approaches to detect them. Therefore, we performed a target and suspect screening based on a persistencemobility prioritization for phytotoxins in small Swiss creeks using high resolution mass spectrometry. In total, three of 26 targets were detected, three of 78 suspects tentatively identified, and six suspects fully confirmed by reference standards. To the best of our knowledge, it is the first time that three different plant secondary metabolite classes are detected in the same surface water sample. Estrogenic isoflavones were detected at $73 \%$ of the sites with formononetin as main toxin, which is in agreement with previous studies. Furthermore, pyrrolizidine alkaloids and the indole alkaloid gramine were detected. Especially pyrrolizidine alkaloids might be critical due to their production by various plants including the invasive Senecio inaequidens, and their known importance in food and feed safety. Based on these first screening results, different phytotoxin classes should be assessed for their ecotoxicological effects and considered in future water monitoring.
\end{abstract}

Keywords: Environmental analytics · Isoflavones · Natural toxins · Pyrrolizidine alkaloids · Suspect screening

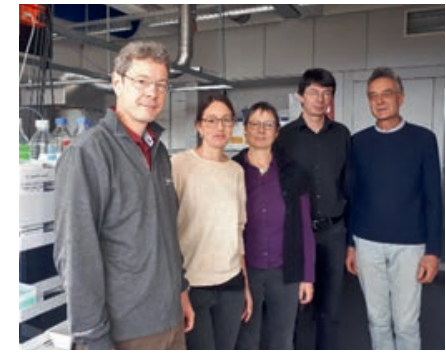

The team working on phytotoxins in the environment. Left to right: Thomas D. Bucheli (group leader Environmental Analytics Agroscope), Barbara F. Günthardt (Doctoral student), Juliane Hollender (Professor and group leader Environmental Chemistry Eawag), Martin Scheringer (Professor), and Konrad Hungerbiihler (Professor emeritus); missing on the picture: Carina D. Schönsee (Doctoral student).

\section{Introduction}

Plants produce numerous different secondary metabolites (PSMs) structurally belonging to various classes, of which alkaloids and terpenes are the most important ones. ${ }^{[1]}$ The concentration of individual PSMs ranges between just a few $\mathrm{g} \mathrm{kg}^{-1}$ up to over $200 \mathrm{~g} \mathrm{~kg}^{-1}$ dry weight. [2] While many show beneficial effects, plants also produce toxic PSMs, named phytotoxins, with widely varying harmful impacts. In most cases, phytotoxins are produced by plants for protection against herbivores, pathogens, or other plant species..$^{[1,3]}$ Nevertheless, phytotoxins may also reach nontarget organisms in terrestrial or possibly even aquatic environments. Indeed, the occurrence of phytotoxins in surface water has previously been demonstrated. For instance, ptaquiloside, a carcinogenic norsesquiterpene glucoside produced by bracken fern (Pteridium aquilinum), can leach into surface water and was even detected in groundwater with concentrations of up to $92 \mathrm{ng} \mathrm{L}^{-1} \cdot{ }^{[4,5]}$ Clover (Trifolium spp.) produces estrogenic isoflavones that were regularly detected in Swiss rivers in the low ng L ${ }^{-1}$ range, but in some cases the concentrations were even above $200 \mathrm{ng} \mathrm{L}^{-1} \cdot{ }^{[6,7]}$ However, environmental exposure or surface water monitoring studies have only been done for a few of the several thousand known phytotoxins. ${ }^{[8]}$

Recently, we published a freely accessible Toxic PlantsPhytotoxins (TPPT) database for Switzerland, accompanied by a preliminary aquatic risk assessment of phytotoxins. ${ }^{[9]}$ All phytotoxins were defined following criteria for persistence, mobility and toxicity (PMT) on the basis of in silico predicted data using a method developed by Arp et al. for anthropogenic compounds. ${ }^{10]}$ Priority phytotoxins were required to i) show a half-life longer than 20 days, ii) have a soil organic carbon-water partition coefficient $\left(\log \mathrm{K}_{\mathrm{oc}}\right)$ or $\mathrm{pH}$-dependent $\log \mathrm{K}_{\mathrm{oc}}\left(\log \mathrm{D}_{\mathrm{oc}}\right)$ of $\leq 4.5$ which indicates compound mobility, iii) be either acute rodent or acute aquatic toxic, and iv) be produced by plants with high abundance in Switzerland. The risk assessment showed that in total 516 phytotoxins have similar properties as anthropogenic compounds commonly found in aquatic monitoring studies, which is over $30 \%$ of all included phytotoxins. Therefore, many more potential phytotoxins of emerging concern might occur in the aqueous environment.

With the development of novel analytical techniques, especially high resolution mass spectrometry (HRMS), improved screening methods have become available. They enable robust and sensitive detections over a wide mass range (up to $2000 \mathrm{Da}$ )

${ }^{*}$ Correspondence: Dr. T. D. Buchelia, E-mail: thomas.bucheli@agroscope.admin.ch

a'Environmental Analytics, Agroscope, Reckenholzstrasse 191, CH-8046 Zurich, Switzerland; bSwiss Federal Institute of Aquatic Science and Technology, Eawag, Überlandstrasse 133, CH-8600 Dübendorf, Switzerland; 'Institute of Biogeochemistry and Pollutant Dynamics, ETH Zürich, Universitätsstrasse 16, CH-8092 Zurich, Switzerland; Institute for Chemical and Bioengineering, ETH Zurich, Wolfgang-Pauli-Strasse 10, CH-8093 Zurich, Switzerland 
with high mass resolution ( $\geq 20$ '000 $(\mathrm{mz} / \Delta \mathrm{mz})$ ) and accuracy $(<5$ ppm). ${ }^{[11]}$ Nowadays, the coupling of liquid chromatography (LC) with electrospray ionization (ESI) to HRMS is a major routine method in environmental trace analysis of pesticides, pharmaceuticals, household or industrial chemicals. ${ }^{[12-14]}$ Often, quantitative analysis with reference standards (target screening) is complemented with suspect screening, where a qualitative assessment of a high number of expected compounds is possible without the need for reference standards. A major requirement of these methods is a functional group ionizable with ESI through the formation of adducts: primarily $[\mathrm{M}+\mathrm{H}]^{+}$in positive mode and $[\mathrm{M}-\mathrm{H}]^{-}$in negative mode. Since phytotoxins show structural features comparable to those of anthropogenic compounds, LC-ESI-HRMS methods should also be largely applicable to phytotoxins.

The goal of this study was to test whether well-established screening approaches and methods for anthropogenic micropollutants are also applicable to phytotoxins of different PSM classes and whether the PMT prioritization identifies candidates that actually occur in surface waters. Furthermore, we aimed at a first overview of phytotoxin occurrence in Swiss surface waters to evaluate if these compounds may be considered as "natural micropollutants' reaching non-target organisms. ${ }^{8]}$ To this end, an initial sampling campaign was carried out during high plant abundance followed by a target and suspect screening using HRMS.

\section{Methods}

For a first phytotoxin screening, 11 surface water sites in the canton of Zurich were sampled (Table 1). The selected sites showed typical vegetation for the Swiss Plateau as defined by InfoFlora.[15] Small creeks were selected based on the plants growing in their catchment areas: each plant known to produce phytotoxins prioritized by Günthardt et al. ${ }^{[9]}$ had to be present in the catchment area of at least one sampling site. Additionally, we ensured that, first, the sites covered different land uses in the catchments, including arable land, grassland and forest, and, second, that the impact of urban areas was low $(\leq 15 \%)$. For each site, one grab sample (1 L) was taken in June 2018 during high plant population and stored at $-20{ }^{\circ} \mathrm{C}$ until analysis.

Sample preparation and analysis followed a method described in detail elsewhere. ${ }^{[16,17]}$ It has been successfully applied in broad screenings for pesticides, pharmaceuticals or their transformation products. Briefly, water samples were enriched with offline solid-phase extraction (SPE) performed on manually prepared cartridges containing five different materials (Oasis HLB, Isolute ENV+, Strata-X-AW, Strata-X-CV, and EnviCarb). Such cartridges achieved good enrichment for a broad range of compounds. ${ }^{[17]}$ Therefore, they were also expected to capture phytotoxins of different PSM classes. The extracts were separated by HPLC on an Atlantis T3 C18 column ( $3 \mu \mathrm{m}, 3.0 \mathrm{~mm}$ i.d. $\times 150 \mathrm{~mm}$, Waters), employing an acidic methanol-water gradient. The analysis was performed with ESI, positive and negative mode in two separate runs, on a Q-Exactive Orbitrap (Thermo Fisher Scientific (San Jose, USA)) measuring full scans (for $\mathrm{m} / \mathrm{z}=100-1200$ at resolution R: 140'000) and data-dependent MS/MS.

Targets and suspects were chosen following the PMT assessment performed by Günthardt et al. ${ }^{[9]}$ From the resulting 516 priority phytotoxins belonging to 12 PSM classes, 26 targets were selected. For each of these classes one to three targets were chosen taking into account the expected measurement suitability and commercial availability of standards. Thus, the PSM classes and phytotoxin targets in this study were as follows: steroids (strophanthidin), terpenoid alkaloids (taxol, aconitine), pyrrolizidine alkaloids (senecionine, echimidine, lycopsamine), steroidal alkaloids (solasodine), isoquinoline alkaloids (berberine, isocorydine, protopine), quinolizidine alkaloids (cytisine, huperzine A, sparteine (Sigma Aldrich, Buchs, Switzerland)), sesquiterpenes (artemisinin, parthenolide), polyketides (daidzein, 8-prenylnaringenin), indole alkaloids (vincamine (Sigma Aldrich), reserpine, gramine (Sigma Aldrich)), triterpenes (cucurbitacin E), diterpenes (10-deacetylbaccatin III, lathyrol), amaryllidaceaea alkaloids (lycorine (Sigma Aldrich), galanthamine), and saponins (diosgenin). If not stated, standards were purchased from PhytoLab (Vestenbergsgreuth, Germany).

Table 1. Description of the surface water sites that were grab-sampled in June 2018.

\begin{tabular}{|c|c|c|c|c|c|c|c|c|}
\hline \multirow[t]{2}{*}{ Site } & \multirow{2}{*}{$\begin{array}{l}\text { Creek or closest } \\
\text { larger creek }^{\mathrm{a}}\end{array}$} & \multirow{2}{*}{$\begin{array}{l}\text { Catchment } \\
\text { size }\left[\mathrm{km}^{2}\right]^{\mathrm{b}}\end{array}$} & \multirow{2}{*}{$\begin{array}{l}\text { Number of plant } \\
\text { species producing } \\
\text { priority phytotoxins } \\
\text { in catchment }{ }^{\mathrm{b}}\end{array}$} & \multirow{2}{*}{$\begin{array}{l}\text { Immediate } \\
\text { vicinity of the } \\
\text { sampling site }\end{array}$} & \multicolumn{4}{|c|}{ Catchment area $^{c}$} \\
\hline & & & & & $\begin{array}{c}\text { Forest } \\
{[\%]}\end{array}$ & $\begin{array}{l}\text { Agricul- } \\
\text { ture [\%] }\end{array}$ & $\begin{array}{l}\text { Urban } \\
\text { area }[\%]\end{array}$ & $\begin{array}{c}\text { Other } \\
{[\%]}\end{array}$ \\
\hline I & Glatt $^{\mathrm{a}}$ & 4.26 & 69 & Arable land & 54 & 36 & 10 & $<1$ \\
\hline II & Sihl $^{\mathrm{a}}$ & 1.96 & 83 & Grassland & 7 & 81 & 8 & 3 \\
\hline III & Chatzenbach & 2.85 & 79 & $\begin{array}{l}\text { Arable land, } \\
\text { grassland }\end{array}$ & 13 & 70 & 15 & 3 \\
\hline IV & Teufenbach & 1.80 & 84 & Forest & 19 & 74 & 4 & 4 \\
\hline V & Wildbach $^{\mathrm{a}}$ & 0.64 & 49 & Forest & 48 & 48 & 5 & 0 \\
\hline VI & Altbach $^{\mathrm{a}}$ & 0.76 & 51 & Arable land & 78 & 18 & 5 & 0 \\
\hline VII & Ruebisbach & 2.93 & 51 & Forest & 29 & 57 & 14 & $<1$ \\
\hline VIII & Töss $^{\mathrm{a}}$ & $<1$ & 61 & Forest & approx. 80 & approx. 15 & $<5$ & 0 \\
\hline IX & Aabach & 5.34 & 87 & $\begin{array}{l}\text { Arable land, } \\
\text { grassland }\end{array}$ & 8 & 83 & 8 & $<1$ \\
\hline $\mathrm{X}$ & Schlegeltobelbach & 1.21 & 58 & Forest & 34 & 62 & 5 & 0 \\
\hline $\mathrm{XI}$ & Niederwiesenbach & 16.0 & 45 & Arable land & 20 & 68 & 9 & 3 \\
\hline
\end{tabular}


Targets were verified by MS/MS fragments and quantified applying the XCalibur 4.1 (Thermo Scientific Corp.) software using an external calibration curve in tap water $\left(0.25 \mathrm{ng} \mathrm{L}^{-1}\right.$ to 500 $\mathrm{ng} \mathrm{L^{-1 }}$ ) and the extracted ion chromatograms of the full scan (mass accuracy $5 \mathrm{ppm}$ ). Limit of detections (LoDs) laid between 0.1 $n g \mathrm{~L}^{-1}$ and $4 \mathrm{ng} \mathrm{L}^{-1}$ for two thirds of the targets and only for three of them (cucurbitacin E, lathyrol, parthenolide) above $20 \mathrm{ng} \mathrm{\textrm {L } ^ { - 1 }}$. Suspect peak lists were automatically generated with Compound Discoverer 2.1 (Thermo Scientific Corp., U.S.) including peak picking, retention time (RT) correction, grouping according to molecular weight and RT, background removal, exclusion below peak area threshold, and suspect annotation. The features were further reduced manually through expert peak evaluation, RT plausibility check and isotope pattern inspection as exemplified below. ${ }^{[11,18]}$ For MS/MS fragment evaluation, priority was set on those suspects belonging to PSM classes for which targets were detected in this study, which resulted in 78 suspects of the total 516 priority phytotoxins. For newly detected suspect candidates, reference standards were purchased if available for final confirmation and quantification.

\section{Results and Discussion}

\subsection{Target and Suspect Confirmation}

Three of 26 target phytotoxins belonging to three different PSM classes were detected at least once in surface waters: the isoflavone daidzein, the indole alkaloid gramine and the pyrrolizidine alkaloid senecionine. In other words, over $10 \%$ of the targets occurred at least once. The highest concentrations were found for gramine with a maximum of $55 \mathrm{ng} \mathrm{L}^{-1}$ and an average concentration (of the detects) of $15 \mathrm{ng} \mathrm{L}^{-1}$. Gramine was also detected at most sites, namely five out of 11. Daidzein was detected at four different sites in concentrations ranging from $1.4 \mathrm{ng} \mathrm{L}^{-1}$ to $5.5 \mathrm{ng} \mathrm{L}^{-1}$. Senecionine was only detected at one site at a concentration of $12 \mathrm{ng} \mathrm{L}^{-1}$.

Suspect candidates from the Compound Discoverer output list were manually reduced as briefly and exemplarily described in the following for the suspect seneciphylline. Using XCalibur, the exact mass trace showed a symmetric peak at a RT of $9.7 \mathrm{~min}$ with a mass accuracy below $5 \mathrm{ppm}\left(\left[\mathrm{C}_{18} \mathrm{H}_{23} \mathrm{NO}_{5}+\mathrm{H}\right]^{+}\right)$. The isotope pattern further confirmed the molecular formula. The potential seneciphylline signal elutes before the target senecionine $(\Delta \mathrm{RT}=-0.9)$, indicating a higher polarity of seneciphylline in reversed phase chromatography. EpiSuite estimated octanolwater partition coefficients $\left(\log \mathrm{K}_{\mathrm{ow}}\right.$ ) show that seneciphylline $\left(\log \mathrm{K}_{\mathrm{ow}}=-1.88\right)$ is more hydrophilic than senecionine $\left(\log \mathrm{K}_{\mathrm{ow}}\right.$ $=-0.39)$, which is structurally explained by the exchange of one of the methyl groups $\left(-\mathrm{CH}_{3}\right)$ in senecionine to a methylidene group $\left(=\mathrm{CH}_{2}\right)$ in seneciphylline. For structural identification, the MS/MS was inspected and the four most intense peaks evaluated manually: exact mass fragments $m / z, 306.1702\left(\mathrm{C}_{17} \mathrm{H}_{24} \mathrm{NO}_{4}{ }^{+}(-\right.$ $\mathrm{CO})), m / z \quad 138.0915\left(\mathrm{C}_{8} \mathrm{H}_{12} \mathrm{ON}^{+}\right), m / z \quad 120.0809\left(\mathrm{C}_{8} \mathrm{H}_{10}^{24} \mathrm{~N}^{+}\right)$, and $m / z 94.0653\left(\mathrm{C}_{6} \mathrm{H}_{8} \mathrm{~N}^{+}\right)$. The three latter product ions were also found in the MS/MS of senecionine and were identified as common ions for all pyrrolizidine alkaloids. Further certainty was achieved through considering the toxin patterns of plant species that produce senecionine, for which seneciphylline was also a major toxin. ${ }^{[9]}$ Finally, the standard was purchased and seneciphylline successfully confirmed.

In total, suspect screening in the described way led to the detection of nine further phytotoxins. We tentatively identified the three isoflavones genistein, formononetin and biochanin $\mathrm{A}$ and six pyrrolizidine alkaloids, i.e. senecionine $\mathrm{N}$-oxide, seneciphylline, seneciphylline $\mathrm{N}$-oxide, retrorsine, retrorsine $\mathrm{N}$-oxide. Besides the target gramine, no other indole alkaloid suspect was found. The isoflavones are known to occur (discussed below), therefore we remained on tentative identification level $2 \mathrm{a}$ according to Schymanski et al ${ }^{[19]}$ For all pyrrolizidine alkaloids, standards were
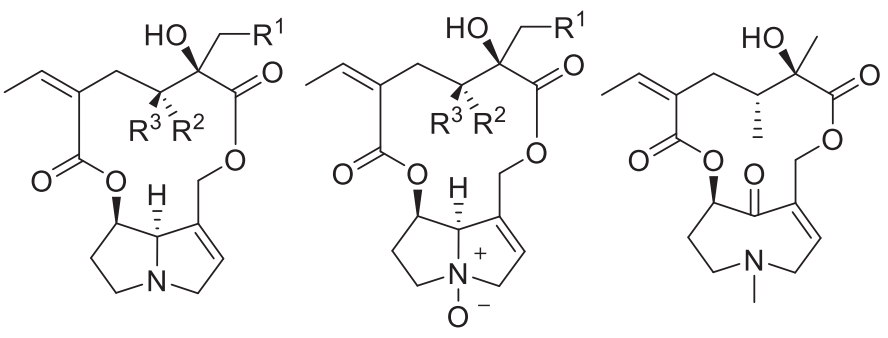

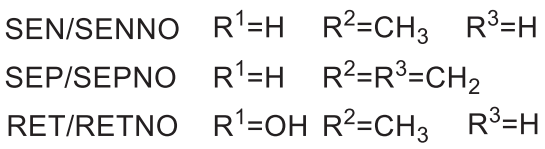
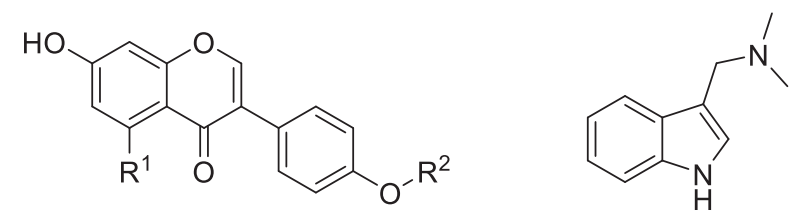

$$
\begin{array}{lll}
\text { DAI } & \mathrm{R}^{1}=\mathrm{H} & \mathrm{R}^{2}=\mathrm{H} \\
\text { GEN } & \mathrm{R}^{1}=\mathrm{OH} & \mathrm{R}^{2}=\mathrm{H} \\
\text { FOR } & \mathrm{R}^{1}=\mathrm{H} & \mathrm{R}^{2}=\mathrm{CH}_{3} \\
\text { BIO } & \mathrm{R}^{1}=\mathrm{OH} & \mathrm{R}^{2}=\mathrm{CH}_{3}
\end{array}
$$

SEK

Fig. 1. Chemical structures of all targets and tentatively identified suspects: senecionine (SEN), senecionine N-oxide (SENNO), seneciphylline (SEP), seneciphylline $\mathrm{N}$-oxide (SEPNO), retrorsine (RET), retrorsine $\mathrm{N}$-oxide (RETNO), senkirkine (SEK), daidzein (DAI), genistein (GEN), formononetin (FOR), biochanin $\mathrm{A}(\mathrm{BIO})$, and gramine.

purchased to fully confirm the structures since these molecules have not been described in surface waters until very recently. ${ }^{[20]}$ Fig. 1 shows all structures of identified phytotoxins and Table 2 gives additional analytical information as well as maximum and average concentrations detected in sampled creeks.

\subsection{Evaluation of the Screening Approach Using the Well-known Isoflavones}

Up to now, isoflavones are probably the best investigated phytotoxin class regarding their occurrence in Swiss surface waters. ${ }^{[6,7,21]}$ As such, they can be used to evaluate the chosen screening approach including its analytical method and sampling strategy. Regarding the analytical method, the measured daidzein concentrations indicate that the chosen method is appropriate. The LoD of daidzein is $0.35 \mathrm{ng} \mathrm{L}^{-1}$, which is very sensitive and below measured estrogenic effect concentrations. ${ }^{[7]}$ Since formononetin, the main phytotoxin produced by Trifolium spp., had even significantly bigger peak areas, the detection of isoflavones in the aquatic environment is well possible with the method presented here. Based on the detected daidzein concentrations and the method LoDs of all other phytotoxins (LoDs were between $0.1 \mathrm{ng} \mathrm{L}^{-1}$ and $4 \mathrm{ng} \mathrm{\textrm {L } ^ { - 1 }}$ for over $66 \%$ of targets), we also conclude that the chosen method is suitable for the screening of most phytotoxins in surface water. Only in the case of approximately $30 \%$ of the compounds, low concentrations $\left(<4 \mathrm{ng} \mathrm{L}^{-1}\right)$ might not be detected.

Isoflavones were detected at nine of the 11 sampled sites. Biochanin A shows a slightly increased occurrence compared with the quantified daidzein (Fig. 2a) in terms of average peak area $\left(4.6 \times 10^{6}\right.$ versus $\left.2.3 \times 10^{6}\right)$. While genistein has smaller peak areas in comparison with daidzein, formononetin always shows larger peak areas than daidzein. From this fact and due to the highly similar chemical structure, we can assume that the formononetin concentrations were higher than those of daidzein (between $1.4 \mathrm{ng} \mathrm{L}^{-1}$ and $5.5 \mathrm{ng} \mathrm{L}^{-1}$ ). Additionally, formononetin was detected at a total of eight sites (i.e. in $73 \%$ of the samples) in contrast to daidzein 
Table 2. Details of the detected phytotoxins in surface water samples (Table 1), including plant secondary metabolite (PSM) class, analytical information, identification confidence, and maximum as well as average detected concentrations.

\begin{tabular}{|c|c|c|c|c|c|c|c|}
\hline Phytotoxin & PSM class & $\begin{array}{l}\text { Retention } \\
\text { time [min] }\end{array}$ & $\begin{array}{c}\text { Precursor ion } \\
m / z^{b}\end{array}$ & $\begin{array}{c}\text { Level of } \\
\text { confidence }^{c}\end{array}$ & $\begin{array}{l}\text { Number } \\
\text { of detects } \\
\text { (total 11) }\end{array}$ & $\begin{array}{c}\text { Maximum } \\
\text { concentration } \\
{\left[\mathrm{ng} \mathrm{L}^{-1}\right]}\end{array}$ & $\begin{array}{c}\text { Average concen- } \\
\text { tration (of detects) } \\
{\left[\mathrm{ng} \mathrm{L}^{-1}\right]}\end{array}$ \\
\hline Gramine $^{\mathrm{a}}$ & Indole alkaloid & 8.6 & 175.1230 & 1 & 5 & 55 & 15 \\
\hline Biochanin A & Isoflavone & 18.6 & 285.0757 & $2 \mathrm{a}$ & 4 & \multicolumn{2}{|c|}{ not quantified } \\
\hline Daidzein $^{\mathrm{a}}$ & Isoflavone & 15.8 & 255.0652 & 1 & 4 & 5.5 & 3.4 \\
\hline Formononetin & Isoflavone & 17.7 & 269.0809 & $2 \mathrm{a}$ & 8 & \multicolumn{2}{|c|}{ not quantified } \\
\hline Genistein & Isoflavone & 17.5 & 271.0601 & $2 \mathrm{a}$ & 4 & \multicolumn{2}{|c|}{ not quantified } \\
\hline Retrorsine & $\begin{array}{l}\text { Pyrrolizidine } \\
\text { alkaloid }\end{array}$ & 9.3 & 352.1755 & 1 & 1 & 3.7 & 3.7 \\
\hline $\begin{array}{l}\text { Retrorsine } \\
\text { N-oxide }\end{array}$ & $\begin{array}{l}\text { Pyrrolizidine } \\
\text { alkaloid }\end{array}$ & 9.5 & 368.1704 & 1 & 1 & 17 & 17 \\
\hline Senecionine $^{\mathrm{a}}$ & $\begin{array}{l}\text { Pyrrolizidine } \\
\text { alkaloid }\end{array}$ & 10.6 & 336.1806 & 1 & 1 & 12 & 12 \\
\hline $\begin{array}{l}\text { Senecionine } \\
\text { N-oxide }\end{array}$ & $\begin{array}{l}\text { Pyrrolizidine } \\
\text { alkaloid }\end{array}$ & 10.8 & 352.1755 & 1 & 1 & 67 & 67 \\
\hline $\begin{array}{l}\text { Seneciphyl- } \\
\text { line }\end{array}$ & $\begin{array}{l}\text { Pyrrolizidine } \\
\text { alkaloid }\end{array}$ & 9.7 & 334.1649 & 1 & 1 & 3.8 & 3.8 \\
\hline $\begin{array}{l}\text { Seneciphyl- } \\
\text { line N-oxide }\end{array}$ & $\begin{array}{l}\text { Pyrrolizidine } \\
\text { alkaloid }\end{array}$ & 10 & 350.1598 & 1 & 1 & 22 & 22 \\
\hline Senkirkine & $\begin{array}{l}\text { Pyrrolizidine } \\
\text { alkaloid }\end{array}$ & 10.7 & 366.1911 & 1 & 1 & 2.0 & 2.0 \\
\hline
\end{tabular}

a targets; ${ }^{b}$ used for quantification; ${ }^{~}$ levels of confidence according to Schymanski et al.: 1 = confirmed structure, $2 a=$ probable structure by library. ${ }^{[19]}$

that was only confirmed at four sites (i.e. in $36 \%$ of the samples). Therefore, formononetin was the dominating isoflavone within the sampled small creeks surrounded by natural vegetation. These results follow literature data, where Hoerger et al. also found formononetin to be the most prominent isoflavone detected in $90 \%$ of the samples with median concentrations ranging from detected to $9.0 \mathrm{ng} \mathrm{L}^{-1}$ and maximum concentrations of up to $217 \mathrm{ng} \mathrm{L}^{-1} \cdot{ }^{[7]}$ Both in literature and in this study, genistein was also the least occurring and lowest concentrated isoflavone. Additionally, formononetin is the most stable of the four isoflavones, which could further explain its dominance. ${ }^{[7]}$ Isoflavones are produced by clover, and especially red clover (Trifolium pratense) is a common pasture plant growing all over Switzerland and producing mainly formononetin and biochanin A. Hence, their regular occurrence in corresponding catchments is plausible. An exemplary sampling site is shown in Fig. 2b, where red clover can be seen between other plants growing in the close surroundings of the sampled creek.

\subsection{Relevance of Alkaloids}

To the best of our knowledge, it is the first time that phytotoxins from two different alkaloid classes, i.e. indole and pyrrolizidine alkaloids, were simultaneously detected in surface water. The indole alkaloid gramine is produced by several different plant species including certain grains and grasses (Graminae), which explains the broad occurrence of this phytotoxin. Moreover, at all five sites where gramine was detected, agricultural fields or grassland dominated the catchment area. Although gramine is toxic to insects, the concentrations were well below measured median le-
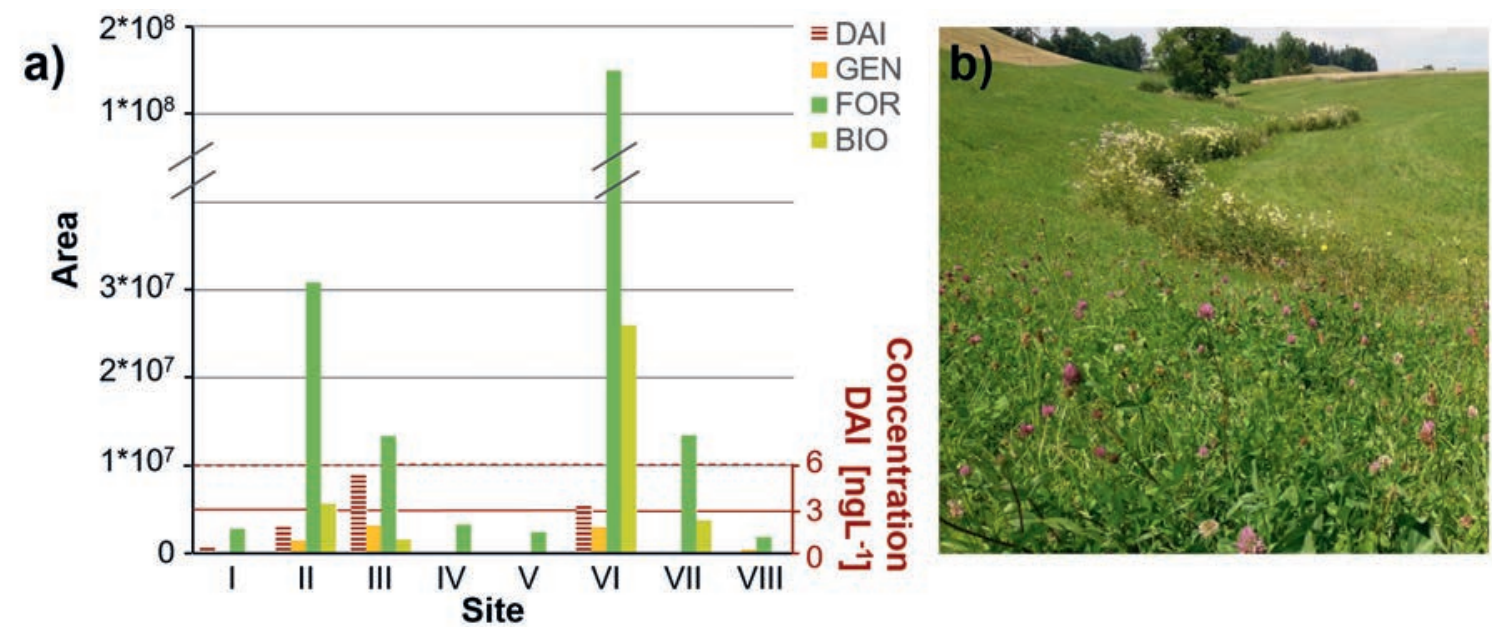

Fig. 2. a) Peak areas for the four isoflavones daidzein (DAI), genistein (GEN), formononetin (FOR), and biochanin A (BIO) as determined in surface waters (for site description, see Table 1). For the target daidzein concentrations are additionally given in red. b) Clover (Trifolium spp.) growing in the proximity of the sampled creek (Site II, foreground). 
thal doses $\left(\mathrm{LD}_{50}\right)$ and thus should not show a pronounced effect. ${ }^{[22]}$ In contrast to the wide occurrence of gramine, the detected pyrrolizidine alkaloids only occurred at one site, the Chatzenbach. However, with a sum concentration of $128 \mathrm{ng} \mathrm{L}^{-1}$, the detected concentrations were more than twice as high as the maximum detected gramine concentration of $55 \mathrm{ng} \mathrm{L}^{-1}$ (Table 2). The pattern of all confirmed pyrrolizidine alkaloids in the Chatzenbach is shown in Fig. 3a. The N-oxides were present in significantly higher concentrations compared with the corresponding free bases, and senecionine N-oxide was the most dominant pyrrolizidine alkaloid followed by seneciphylline $\mathrm{N}$-oxide and retrorsine $\mathrm{N}$-oxide. Senecionine N-oxide was found to be the primary pyrrolizidine alkaloid produced in the roots of Senecio spp., ${ }^{[23]}$ which can explain its dominance. Due to different chemotypes, the toxin pattern varies strongly even within one species, ${ }^{[24,25]}$ and therefore no single species can be allocated as primary source in this first study. Nevertheless, the most probable plants are of the genus Senecio spp., of which approximately 20 different species grow in Switzerland. According to the InfoFlora database, S. aquaticus, S. errucifolius, S. inaequidens, S. jacobea, S. ovatus, S. paludosus, $S$. viscosus and $S$. vulgaris can potentially be found in the sampling area. ${ }^{[15]}$ Indeed, we were able to confirm the physical presence of $S$. inaequidens and $S$. jacobea by visual inspection (Fig. 3b). Whereas $S$. jacobea is a domestic plant growing along streets or edges of forests and meadows, $S$. inaequidens originates from South Africa. It is characterized as invasive in Switzerland and spreads along major traffic routes. Therefore, the canton of Zurich fights the spread of this plant, also in the sampling area. ${ }^{[26]}$ Nevertheless, it remains unknown which Senecio spp. was the main source of the pyrrolizidine alkaloids found in this study and if the invasive species generally triggers increased levels in surface waters. In food and feed safety, pyrrolizidine alkaloids are considered as one of the PSM classes with the highest negative impact on livestock and human health. ${ }^{[27]}$ Approximately 3\% of all flowering plants produce them, resulting in contamination of teas, honey and to lesser extent animal products. ${ }^{[22-23]}$ Therefore, occurrence in surface water could even increase their importance, particularly with regards to the safety of the environment and drinking water resources.

\subsection{Further PSM Classes Containing Priority Phytotoxins}

In this study, phytotoxins from different compound classes were detected in Swiss surface water. Not only do the results con- firm the applicability of the chosen HRMS-based screening method, but they also confirm that the prioritization approach proposed by Günthardt et al. ${ }^{[9]}$ provided reasonable candidates for subsequent suspect screening. In Fig. 4, the results of the prioritization approach are visualized by displaying the average Swiss plant frequency, the percentage of the Swiss land area in which a plant species is found as defined by Info Flora, ${ }^{[15]}$ in connection with the different PSM classes and the phytotoxins average PM score. The PM score ranks organic compounds for being persistent and mobile based on the half-life of biodegradation and hydrolysis, and the in silico predicted $\mathrm{pH}$-dependent soil-organic carbon water partition coefficient $\left(\mathrm{D}_{\mathrm{oc}}\right) .{ }^{[9,10]}$ The majority of phytotoxins detected in this study belong to PSM classes showing an average phytotoxin PM score higher than three and an average Swiss plant frequency over $40 \%$. Thus, not only the intrinsic phytotoxin properties but also phytotoxin production indicated by plant abundance plays a major role in potential phytotoxin occurrence in surface waters. In the case of isoflavones (polyketides, Fig. 4/a), the average Swiss plant frequency exceeds $90 \%$ for all identified compounds, explaining why even genistein and daidzein can be detected although they are predicted to be rather unstable. In contrast, the major source of the indole alkaloid gramine (Fig. 4/b) is agricultural plants such as Hordeum vulgare or Lupinus luteus belonging to a category that is not accounted for in the average Swiss plant frequency. ${ }^{[9]}$ Thus, gramine is found in catchments with substantial agricultural influence despite falling into a PM category that does not show high overall source-plant frequency. In such hotspots, characterized by a substantial toxic plant biomass in a restricted area, phytotoxins may frequently be detected. This is also shown for the pyrrolizidine alkaloids (Fig. 4/c) potentially originating from the invasive Senecio spp., or the well-described ptaquiloside (Fig. 4/d) from Bracken fern. ${ }^{[4,5]}$ The general trend as seen in Fig. 4 suggests that particularly phytotoxins from the alkaloid and terpenoid PSM classes may be potential detects in other study areas in Switzerland as they show, on average, a higher PM score than phytotoxins from other PSM classes. When expanding the monitoring to regions outside of Switzerland, the overall prioritization needs to be performed again to account for the presence of other toxic plants and possibly other phytotoxins.

\subsection{Ecotoxicological Relevance and Future Research}

To assess the risk of phytotoxins, ecotoxicological effect data is needed. However, very few measured data are available and preliminary assessments were only provided by few individual
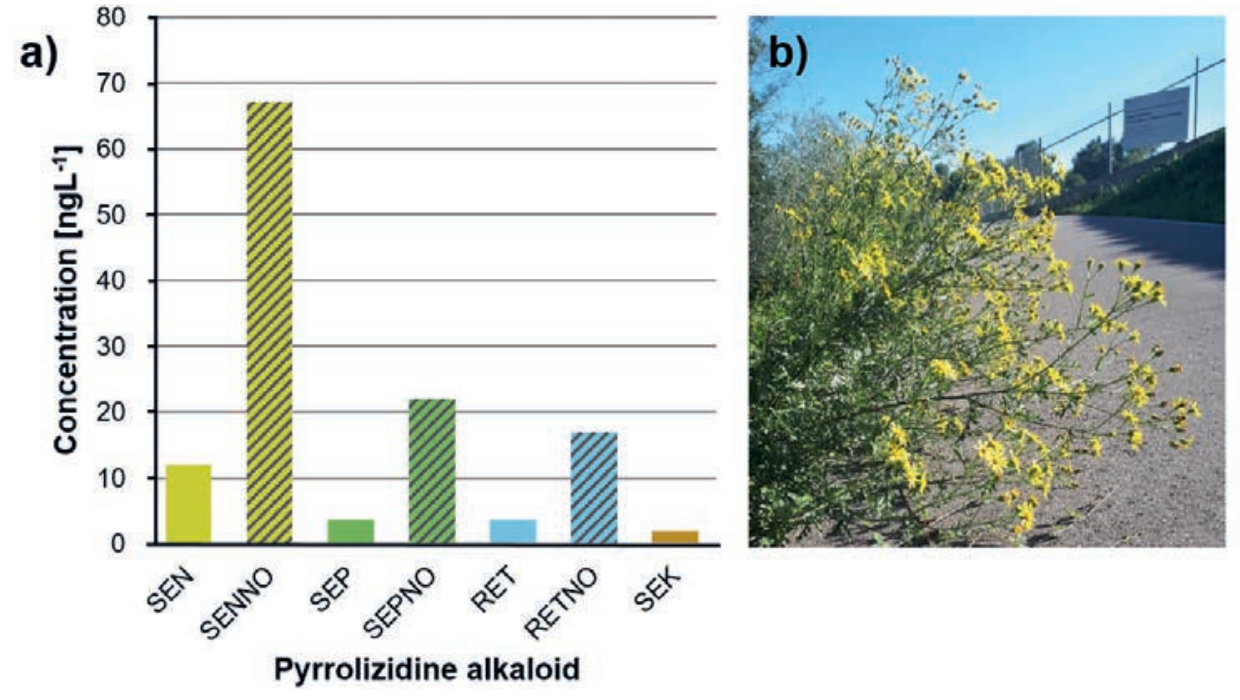

Fig. 3. a) Concentrations of the different pyrrolizidine alkaloids and their N-oxides detected in the Chatzenbach (site III): senecionine (SEN), senecionine N-oxide (SENNO), seneciphylline (SEP), seneciphylline N-oxide (SEPNO), retrorsine (RET), retrorsine N-oxide (RETNO) and senkirkine (SEK). b) Senecio jacobea in the proximity of the Chatzenbach (site III) as an exemplary plant producing pyrrolizidine alkaloids. 


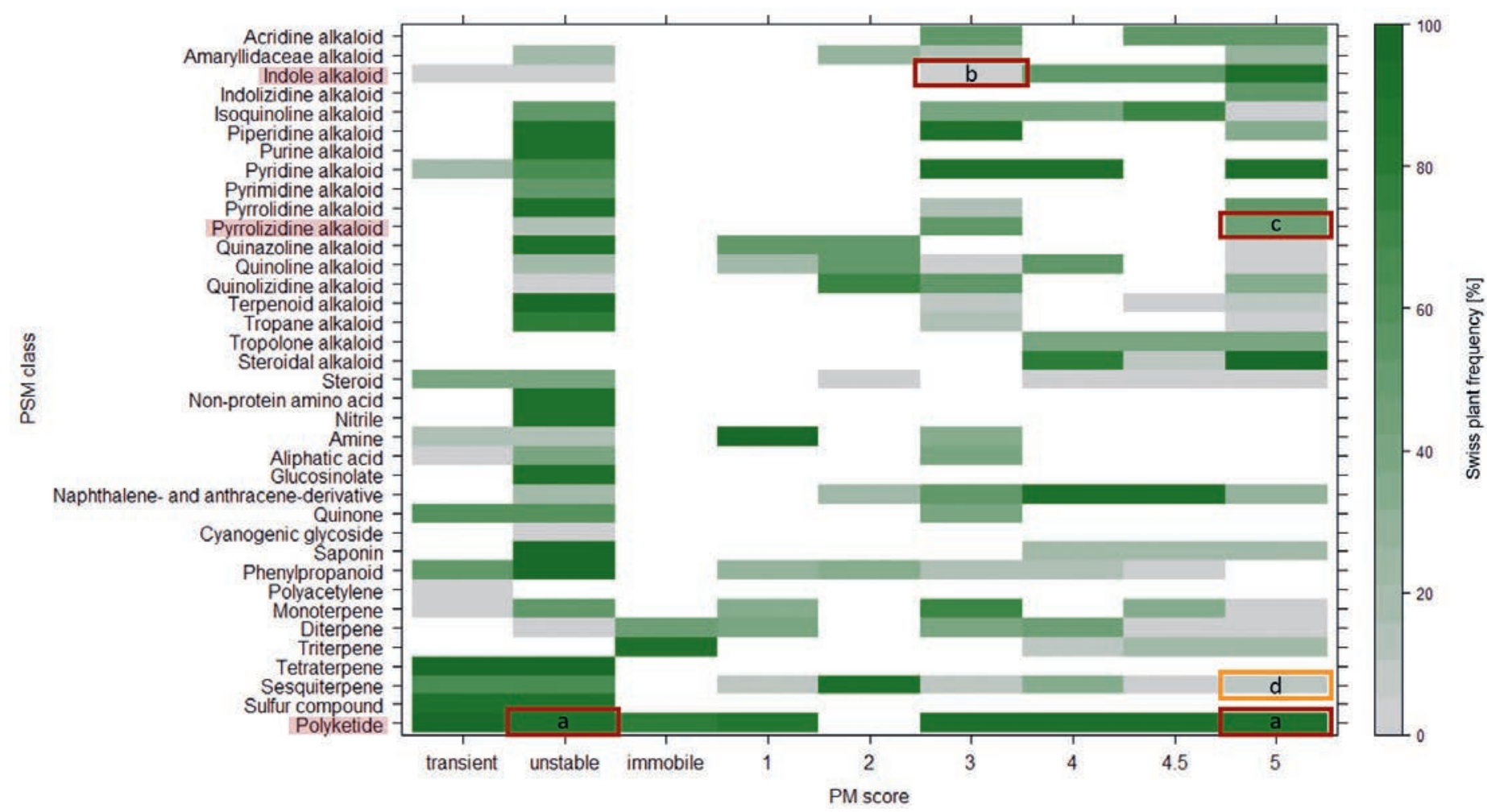

Fig. 4. Average Swiss plant frequency plotted according to the phytotoxins' respective PSM classes and predicted, average PM scores (persistence and mobility). Displayed data is taken from the Toxic Plants-Phytotoxins database by Günthardt et al. without any further amendment. ${ }^{[9]}$ The Swiss plant frequency is the average percentage of the Swiss land area in which plant species producing phytotoxins of a certain PSM class are found as defined by Info Flora. ${ }^{[15]}$ It gives a tendency on those PSM classes, of which phytotoxins are more likely to be produced in higher amounts. The higher the PM score, the more likely a compound can be found in the aqueous environment. Representatives of highlighted categories (a)-(c) were detected in this study, while category (d) includes the well-studied ptaquiloside from Bracken fern.

case studies for single compounds such as ptaquiloside, artemisinin, batatasin III, or the biopesticides rotenone and azadirachtin (for details, see Bucheli ${ }^{[8]}$ ). The regularly occurring isoflavones were shown to pose limited risk, primarily because their estrogenic activities are three to four orders of magnitude lower than those of $17 \beta$-estradiol. ${ }^{[7]}$ The pyrrolizidine alkaloids' chronic effect concentrations in the aquatic environment as predicted by the U.S. EPA's ecological structure-activity relationships (ECOSAR) model ${ }^{[29]}$ were in the low $\mathrm{mg} \mathrm{L}^{-1}$ range, which was by far not reached in our studies. However, the occurrence of phytotoxins in general might still be of relevance in light of, e.g., their potential mixture toxicity alone or in combination with anthropogenic compounds. In conclusion, based on both the prioritization results and the insights gained from the screening performed in this study, we suggest the following for future investigations on phytotoxins as 'natural micropollutants' in surface waters: 1) adapt the TPPT database and phytotoxin prioritization based on local plant abundance, 2) determine ecotoxicological effect data, and 3) include corresponding priority phytotoxins in the regular monitoring of surface waters to account for the exposure to potentially toxic natural products.

\section{NaToxAq and PHYCROPOLL}

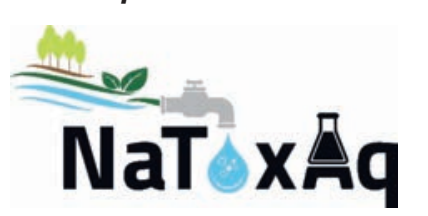

Natural toxins, with the exception of cyanotoxins, are generally not yet regarded as environmental contaminants of concern for water quality. However, the occurrence of mycotoxins and phytotoxins in surface water bodies has indeed been demonstrated in studies of selected single compounds. The NaToxAq project (http://natoxaq.eu), in line with the Swiss project PHYCROPOLL, now aims to obtain a deep insight on natural toxins as environmental contaminants to ensure the production of clean drinking water. The focus is on origin, distribution and fate of natural toxins as emerging aquatic pollutants and potential remediation strategies.

\section{Acknowledgements}

This work received funding from the Swiss National Science Foundation within the project PHYCROPOLL and the European Union's Horizon 2020 research and innovation program under the Marie Sklodowska-Curie grant agreement No. 722493 (NaToxAq). We thank Daniela Rechsteiner for many fruitful discussions and Felix Wettstein, Simon Mangold, Birgit Beck, Philipp Longree and Bernadette Vogler for practical advice.

Received: November 15, 2019

[1] M. Wink, Phytochemistry 2003, 64, 3, doi: 10.1016/S0031-9422(03)00300-

[2] A. Poutaraud, A. Michelot-Antalik, S. Plantureux, J. Agric. Food. Chem. 2017, 65, 6535, doi: 10.1021/acs.jafc.7b00425.

[3] U. Wittstock, J. Gershenzon, Curr. Opin. Plant Biol. 2002, 5, 300, doi: 10.1016/S1369-5266(02)00264-9.

[4] L. H. Rasmussen, H. C. B. Hansen, D. Lauren, Chemosphere 2005, 58, 823, doi: 10.1016/j.chemosphere.2004.08.088

[5] F. Clauson-Kaas, P. H. Jensen, O. S. Jacobsen, R. K. Juhler, H. C. B. Hansen, Environ. Toxicol. Chem. 2014, 33, 1030, doi: 10.1002/etc. 2533.

[6] N. Hartmann, M. Erbs, F. E. Wettstein, C. C. Hoerger, S. Vogelgsang, H.R. Forrer, R. P. Schwarzenbach, T. D. Bucheli, Chimia 2008, 62, 364, doi: 10.2533/chimia.2008.364.

[7] C. C. Hoerger, F. E. Wettstein, K. Hungerbuehler, T. D. Bucheli, Environ. Sci. Technol. 2009, 43, 6151, doi: 10.1021/es901034u.

[8] T. D. Bucheli, Environ. Sci. Technol. 2014, 48, 13027, doi: 10.1021/ es504342w.

[9] B. F. Günthardt, J. Hollender, K. Hungerbühler, M. Scheringer, T. D. Bucheli, J. Agric. Food. Chem. 2018, 66, 7577, doi: 10.1021/acs.jafc.8b01639.

[10] H. P. H. Arp, T. N. Brown, U. Berger, S. E. Hale, Environ. Sci.: Proc. Impacts 2017, 19, 939, doi: 10.1039/C7EM00158D

[11] J. Hollender, E. L. Schymanski, H. P. Singer, P. L. Ferguson, Environ. Sci. Technol. 2017, 51, 11505, doi: 10.1021/acs.est.7b02184

[12] J. Hollender, M. Bourgin, K. B. Fenner, P. Longrée, C. S. McArdell, C. Moschet, M. Ruff, E. L. Schymanski, H. P. Singer, Chimia 2014, 68, 793 , doi: 10.2533 /chimia. 2014.793 
[13] C. Hug, N. Ulrich, T. Schulze, W. Brack, M. Krauss, Environ. Pollut. 2014, 184, 25, doi: 10.1016/j.envpol.2013.07.048

[14] A. C. Chiaia-Hernandez, E. L. Schymanski, P. Kumar, H. P. Singer, J. Hollender, Anal. Bioanal. Chem. 2014, 406, 7323, doi: 10.1007/s00216014-8166-0.

[15] K. Lauber, G. Wagner, A. Gygax 'Flora Helvetica - Illustrierte Flora der Schweiz', Haupt Verlag, 2012.

[16] S. Kern, K. Fenner, H. P. Singer, R. P. Schwarzenbach, J. Hollender, Environ. Sci. Technol. 2009, 43, 7039, doi: 10.1021/es901979h.

[17] N. A. Munz, F. J. Burdon, D. de Zwart, M. Junghans, L. Melo, M. Reyes, U. Schönenberger, H. P. Singer, B. Spycher, J. Hollender, C. Stamm, Water Res. 2017, 110, 366, doi: 10.1016/j. watres.2016.11.001.

[18] K. Kiefer, A. Müller, H. Singer, J. Hollender, Water Res. 2019, 165, 114972 doi: 10.1016/j.watres.2019.114972.

[19] E. L. Schymanski, J. Jeon, R. Gulde, K. Fenner, M. Ruff, H. P. Singer, J. Hollender, Environ. Sci. Technol. 2014, 48, doi: 10.1021/es5002105.

[20] J. R. Hama, B. W. Strobel, RSC Advances 2019, 9, 30350, doi: 10.1039/ C9RA05301H.

[21] D. W. Kolpin, C. C. Hoerger, M. T. Meyer, F. E. Wettstein, L. E. Hubbard, T. D. Bucheli, J. Environ. Qual. 2010, 39, 2089, doi: 10.2134/jeq2010.0121.

[22] L. J. Corcuera, Phytochemistry 1984, 23, 539, doi: 10.1016/S00319422(00)80376-3.

[23] T. Hartmann, G. Toppel, Phytochemistry 1987, 26, 1639, doi: 10.1016/ S0031-9422(00)82261-X.

[24] A. Eller, R. Chizzola, Plant Biosystems 2016, 150, 1306, doi: 10.1080/11263504.2015.1054449.

[25] M. Macel, K. Vrieling, P. G. L. Klinkhamer, Phytochemistry 2004, 65, 865, doi: 10.1016/j.phytochem.2004.02.009.
[26] AWEL (Amt für Abfall, Wasser, Energie und Luft): Invasive Neophyten (Pflanzen) (in German). https://awel.zh.ch/internet/baudirektion/awel/de/ biosicherheit_neobiota/neobiota/invasive_Neophyten.html\#title-contentinternet-baudirektion-awel-de-biosicherheit_neobiota-neobiota-invasive_ Neophyten-jcr-content-contentPar-textimage_3, accessed 11.09.2019.

[27] D. Selmar, C. Wittke, I. Beck-von Wolffersdorff, B. Klier, L. Lewerenz, M. Kleinwächter, M. Nowak, Environ. Pollut. 2019, 248, 456, doi: 10.1016/j. envpol.2019.02.026.

[28] FOEN (Federal Office for the Environment): Einzugsgebietsgliederung Schweiz (in German). https://www.bafu.admin.ch/bafu/de/home/themen wasser/zustand/karten/einzugsgebietsgliederung-schweiz.html, accessed 28.10.2019.

[29] Ecological Structure Activity Relationships (ECOSAR) Predictive Model, v. 2.0, United States Environmental Protection Agency, Washington (USA), 2017

\section{License and Terms}

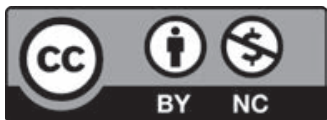

This is an Open Access article under the terms of the Creative Commons Attribution License CC BY_NC 4.0. The material may not be used for commercial purposes.

The license is subject to the CHIMIA terms and conditions: (http:// chimia. .ch/component/sppagebuilder/?view = page \&id=12).

The definitive version of this article is the electronic one that can be found at doi:10.2533/chimia.2020.129 